\title{
Reflets
}

Revue ontaroise d'intervention sociale et communautaire

\section{Sulak Sivaraksa, Seeds of Peace: A Buddhist Vision for Renewing Society, Parallax Press, 1992,140 pages}

Volume 12, numéro 1, 2006

Spiritualité et intervention sociale

URI : https://id.erudit.org/iderudit/013452ar

DOI : https://doi.org/10.7202/013452ar

Aller au sommaire du numéro

Éditeur(s)

Reflets : Revue ontaroise d'intervention sociale et communautaire

ISSN

1203-4576 (imprimé)

1712-8498 (numérique)

Découvrir la revue

Citer ce compte rendu

(2006). Compte rendu de [Sulak Sivaraksa, Seeds of Peace: A Buddhist Vision for Renewing Society, Parallax Press, 1992,140 pages]. Reflets, 12(1), 221-222.

https://doi.org/10.7202/013452ar

Tous droits réservés (C) Reflets : Revue ontaroise d'intervention sociale et communautaire, 2006
Ce document est protégé par la loi sur le droit d'auteur. L'utilisation des services d'Érudit (y compris la reproduction) est assujettie à sa politique d'utilisation que vous pouvez consulter en ligne.

https://apropos.erudit.org/fr/usagers/politique-dutilisation/ 


\section{Seeds of Peace}

\section{Sulak Sivaraksa, $A$ Buddhist Vision for Renewing Society, Parallax Press, 1992,140 pages}

Moine bouddhiste engagé socialement, économiste, activiste, philosophe, l'auteur propose ici une vision de la société basée sur les principes d'un bouddhisme engagé. Pour lui, la spiritualité est au cœur d'une transformation socio-économico-politique qui se manifeste en particulier dans des notions de justice sociale et d'égalité (hommes-femmes, nord-sud) tout en respectant les enfants, les personnes défavorisées, l'histoire. Le modèle de société qu'il propose est basé sur la non-violence, la cohabitation pacifique; pour y parvenir, il suggère neuf principes d'engagement essentiels à tout citoyen, peu importent sa race, son statut, ses croyances. Ces principes visent la survie et l'épanouissement des cultures, des régions, des individus opprimés par les valeurs occidentales capitalistes axées sur la consommation et par un certain modèle de développement qui détruit les assises de notre survie.

Qui plus est, Sivaraksa applique ces préceptes à sa propre situation : la culture thaï, longtemps malmenée par une dictature féroce. Il fut d'ailleurs emprisonné et longtemps condamné à l'exil. Il a fondé et dirige toujours The International Networks of Engaged Buddists, (http://www.sulak-sivaraksa.org/network22.php) et Spirit in Education Movement, une association non gouvernementale visant la promotion d'une éducation alternative.

Auteur de nombreux textes, Sivaraksa a prononcé des centaines de conférences sur l'engagement citoyen. Il propose comme modèle une communauté sangha, symbole de respect pour soi, pour l'autre, et d'une vie harmonieuse.

Voici les neuf principes qu'il propose et desquels le service social pourrait s'inspirer :

- Une réponse transnationale à l'internationalisation du capital; 
- Une solidarité politique et économique des pays du sud quand ils négocient avec les pays du nord;

- Le contrôle des armes de destruction, la résolution juste et pacifique des conflits et le maintien de la sécurité internationale;

- Une diminution des pratiques et de la philosophie de consommation;

- La démocratie,l'égalité, la décentralisation dans les organisations qui devraient représenter les individus plutôt que les nations fortes;

- Un désarmement au niveau planétaire;

- Un système de justice international efficace;

- Une force internationale de maintien de la paix efficace, permanente, forte;

- Un système universel de lois.

Son objectif est d'éveiller les humains à d'autres valeurs que celles que nous proposent aujourd'hui nos dirigeants politiques. En cela, le bouddhisme engagé peut servir de modèle.

\section{Autobiography of a Yogi}

\section{Paramahansa Yogananda,}

Self-Relization Fellowship, 1998, 486 pages

Traduit en plus de vingt langues et vendu à plusieurs millions d'exemplaires, ce livre connaît un succès remarquable depuis sa publication en 1946. Les critiques l'ont hautement acclamé parce qu'il présente de façon simple l'évolution spirituelle de la conscience. Il ne s'agit donc pas d'un livre ordinaire. De l'avis de plusieurs, il a non seulement le potentiel de déclencher une révolution spirituelle, mais il y contribue dans les faits.

Paramahansa Yogananda raconte sa vie, et les chemins qui l'ont amené à la réalisation. Ce faisant, il nous initie au yoga, à la méditation, aux lois qui gouvernent les mondes intérieurs de l'intuition et de la transcendance. 